\title{
Carnitine during Prolonged Breast Feeding
}

\author{
LIISA M. ROVAMO, LEENA SALMENPERÄ, PIRKKO ARJOMAA, AND KARI O. RAIVIO \\ Children's Hospital, University of Helsinki, Helsinki, Finland
}

\begin{abstract}
To assess carnitine levels during prolonged sole breast feeding we measured serum and breast milk carnitine concentrations in $\mathbf{3 7}$ lactating mothers and their healthy term infants from birth to the age of $1 \mathrm{yr}$. The number of solely breast-fed infants decreased to 31 at 2 months of age, to 28 at 6 months, and to seven at 9 months, because formula and/or solid food was added when there was not enough breast milk. In mothers the mean serum carnitine increased from 35 to $50 \mu \mathrm{mol} /$ liter during the first 2 months after delivery and remained unchanged thereafter. Irrespective of the type of feeding, the mean serum carnitine in infants increased from 29 to $59 \mu \mathrm{mol} / \mathrm{liter}$ during the first 2 months, remained unchanged during 2-9 months, and decreased to the mean level of mothers thereafter. The mean carnitine concentration of breast milk was high (106 $\mu \mathrm{mol} / \mathrm{liter})$ immediately after delivery. During the first 2 months the mean carnitine concentration of milk decreased to the mean serum level of mothers and remained unchanged thereafter. The carnitine concentrations of serum and breast milk did not correlate, however. The mean daily carnitine intake of the breast-fed infants was $5.7 \mu \mathrm{mol} / \mathrm{kg}$ at $4 \mathrm{months}$ of age, $4.7 \mu \mathrm{mol} / \mathrm{kg}$ at 6 months, and $6.0 \mu \mathrm{mol} / \mathrm{kg}$ at 9 months whereas the mean daily carnitine intake of the infants receiving formula was 28.9 $\mu \mathrm{mol} / \mathrm{kg}$ at $1 \mathrm{month}$ of age and $30.7 \mu \mathrm{mol} / \mathrm{kg}$ at 2 months. The serum concentration of carnitine in our infants did not correlate with carnitine intake. Our results indicate that serum carnitine concentrations are maintained during prolonged sole breast feeding. (Pediatr Res 20: 806-809, 1986)
\end{abstract}

Carnitine is essential for the utilization of long chain fatty acids: it facilitates their transport across the mitochondrial membrane for $\beta$-oxidation (1).

Carnitine is not an essential nutrient for adults because they synthesize the carnitine they need (1-3). Newborn infants may not, however, be capable of sufficient carnitine synthesis. During carnitine-free soybean-based formula (4-6) or during total parenteral nutrition (7-11) newborn infants have reduced blood, urine, and tissue concentrations of carnitine and retarded ketogenesis, which become corrected only after supplementation with carnitine (12-14). The ability of neonates to synthesize carnitine seems to be limited by the low activity of hepatic $\gamma$-butyrobetaine hydroxylase (15).

For newborn infants the natural source of carnitine is mothers' milk. Two days after birth, serum carnitine and ketone bodies are higher in breast-fed than formula-fed infants, although breast milk and the formula used had similar carnitine concentrations (16). Carnitine concentration in breast milk, however, decreases

Received January 29, 1986; accepted Aprii 7, 1986.

Reprint requests Liisa Rovamo, M.D., Children's Hospital, University of Helsinki, Stenbäckinkatu 11, SF-00290 Helsinki, Finland.

Supported by Foundation for Pediatric Research, Foundation of Nutrition Research, Finnish Cultural Foundation, Academy of Finland, and Huhtamäki Inc., Leiras Pharmaceuticals. during the first weeks after delivery $(17,18)$. Hence, because of possibly insufficient carnitine synthesis, solely breast-fed infants may develop reduced serum carnitine levels during the first months of life.

In the present study we measured carnitine concentrations from the serum of solely breast-fed infants and their lactating mothers during the first year after delivery. In addition, we measured carnitine levels in breast milk and calculated the intake of carnitine during prolonged sole breast feeding.

\section{MATERIALS AND METHODS}

Subjects. The subjects of this study are a subgroup from a follow-up study of 200 infant-mother pairs (19). The study protocol was approved by the Ethical Committee of the Children's Hospital, University of Helsinki, and is in accordance with the Helsinki Declaration.

We studied 37 infants, 24 girls and 13 boys, born to healthy, nonsmoking mothers without pregnancy complications. Three infants were delivered by cesarean section, the others through the vaginal route. All infants were born at term (37-42 wk of gestation) and their birth weights were appropriate for the gestational ages. All infants had normal Apgar scores of 7 to 10 at 1 min of age. The mean birth weight was $3369 \mathrm{~g}$ (range 2740$4040 \mathrm{~g}$ ), and the mean birth length was $49.7 \mathrm{~cm}$ (range 47-51 $\mathrm{cm})$.

Feeding of infants. All 37 mothers were encouraged to feed their infants solely from the breasts. The number of solely breastfed infants was 31 at 2 months of age, 28 at 6 months, 7 at 9 months, and none at 12 months. The mean protein concentration of breast milk decreased from 13 to $8 \mathrm{~g} /$ liter whereas the mean fat concentration increased from 26 to $40 \mathrm{~g} /$ liter during lactation (19). All lactating mothers received supplementary iron and vitamins. Formula and solid food were started when there was not enough breast milk. The formula (Tutteli by Valio, Finnish Co-operative Dairy's Association, Helsinki, Finland) conformed to the FAO/WHO recommendations and contained $16 \mathrm{~g} /$ liter of protein (of which $60 \%$ whey), $35 \mathrm{~g} /$ liter fat (polyunsaturated/saturated ratio 0.33 ), and $73 \mathrm{~g} /$ liter lactose, corresponding to the lactose concentration of breast milk. The total carnitine concentration of the formula was $204 \mu \mathrm{mol} / \mathrm{liter}$. Beginning from the age of 3 months, the infants received solid food which consisted of fruits and vegetables. Cereals and meat were added at the age of 5 months. The formula was replaced with cow's milk at the age of 9 months.

Follow-up. All infants were examined and their weight, length, and skinfold thickness measured every 1-2 months during the first year of life at the Children's Hospital, University of Helsinki (19). Except for mild upper respiratory infections, otitis media, and diarrhea, the infants were healthy. After the age of 3 months the solely breast-fed infants grew slower and had more subcutaneous fat than the weaned infants (19).

Blood and milk samples. A sample from mixed cord blood was taken at birth whereas the first blood sample from the mother was taken on the 3rd or 4th day after delivery. Peripheral venous samples of $5 \mathrm{ml}$ were taken 2, 6, 9, and 12 months after birth. 
The samples from the infants were taken $2-3 \mathrm{~h}$ after breakfast whereas the mothers fasted overnight.

To produce a milk sample at $0,2,4,6,7.5$, and 9 months after delivery, all lactating mothers collected $10 \mathrm{ml}$ of milk before and after each feeding during $24 \mathrm{~h}$. The volume of milk consumed daily was assessed by weighing the infants before and after each feeding during a period of $72 \mathrm{~h}$. The volumes consumed were $705 \mathrm{ml}$ (range $510-845 \mathrm{ml}, n=7$ ) at 4 months of age, 780 $\mathrm{ml}$ (range $500-1025 \mathrm{ml}, n=17$ ) at 6 months, and $910 \mathrm{ml}$ (range $730-1090 \mathrm{ml}, n=5$ ) at 9 months. The amount of formula consumed daily was calculated as the average consumption during four days. The volume consumed was 590 (range 500$610, n=3$ ) at 1 month of age and $770 \mathrm{ml}$ (range 440-1100, $n=$ 4) at 2 months.

Carnitine assays. To avoid caramel formation during alkaline hydrolysis of milk samples, we modified the method of Sandor et al. (18) according to Robles-Valdes et al. (20). The sample was first sonicated, diluted with distilled water in volumes 1 to 4 , and resonicated. Part of the sample was then used for the measurement of free carnitine concentration. The rest was hydrolyzed in $0.1 \mathrm{M} \mathrm{KOH}$ at $37^{\circ} \mathrm{C}$ for $60 \mathrm{~min}$. After neutralization and sonication it was used for the measurement of the total carnitine. Acylcarnitine was calculated by subtracting free carnitine from the total carnitine.

The total and free carnitine concentrations of milk and the total carnitine concentration of serum were measured with the radioisotopic method of McGarry and Foster (21), modified according to Novak et al. (8). Free carnitine of serum was not measured because the volumes of the serum samples were too small. $\left(1-{ }^{14} \mathrm{C}\right)$ acetyl-coenzyme A (specific activity $56.6 \mathrm{mCi}$ / $\mathrm{mmol}$ ) was purchased from Amersham, England, carnitine acetyltransferase (600 kU/liter) from Boehringer Mannheim $\mathrm{GmbH}$, West Germany, and carnitine and acetyl carnitine from Sigma, St. Louis, MO. Recoveries were $95.7 \%$ for free carnitine and $99.1 \%$ for acetyl carnitine but only $34.5 \%$ for palmitoylcarnitine (purchased from Sigma-Tau, Rome, Italy). Recoveries were similar for the serum and milk samples. A hydrolysis of $6 \mathrm{~h}$ did not improve the recovery of palmitoylcarnitine. The interassay coefficients of variation were 4.4 and $5.5 \%$ for free carnitine of serum and milk and 3.4 and $7.2 \%$ for the total carnitine of serum and milk.

We also measured the carnitine concentration of a few milk samples with the method of Warshaw and Curry (16): the fat was first centrifuged and the sample was then deproteinized by perchloric acid before alkaline hydrolysis. The concentrations of free and total carnitine were $12-27 \%$ higher than those measured without fat removal, probably because milk fat does not contain much carnitine.

Statistical analysis. Statistical analyses were performed with the BMDP statistical software (22). Two-way analysis of variance for repeated measurements of carnitine was performed with time as a within factor. Fixed-time comparisons of measurements between three groups were performed with one-way analysis of variance and unpaired $t$ tests. Simple linear correlations were computed between the total, free, and acylcarnitine concentrations.

\section{RESULTS}

Serum carnitine concentrations. The mean total carnitine concentration in the serum of our mothers increased $(p<0.0001)$ from 35 to $50 \mu \mathrm{mol} /$ liter during the first 2 months after delivery and remained unchanged thereafter (Fig. 1). Irrespective of the type of feeding, the mean total carnitine concentration in the serum of our infants also increased $(p<0.0001)$ from 29 to 50 $\mu \mathrm{mol} /$ liter during the first 2 months, remained unchanged during months $2-9$, and decreased $(p<0.001)$ thereafter (Fig. 1).

Immediately after delivery the mean total carnitine concentration was higher $(p<0.0001)$ in the serum of the mothers than in the mixed cord blood. During months 2-9 the mean total

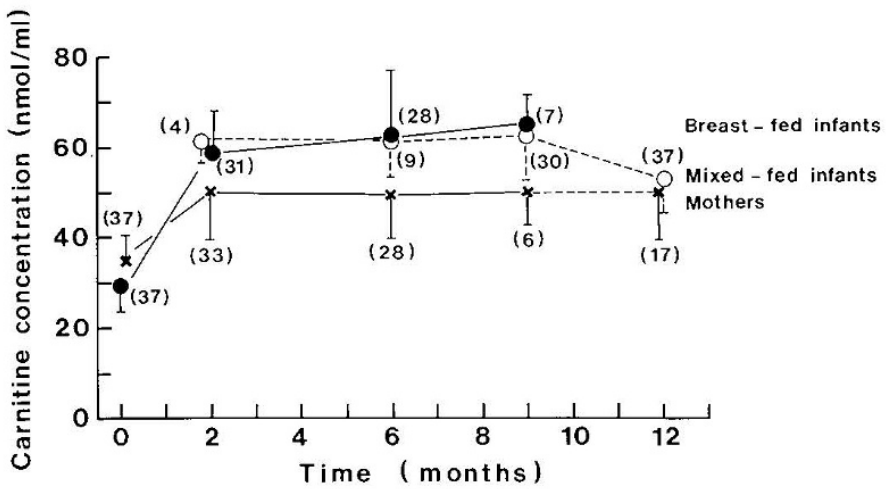

Fig. 1. Serum carnitine in mothers and infants during the first year after birth. The total carnitine concentrations in the serum of breast-fed infants (closed circles) and their mothers (crosses) during prolonged breast feeding in comparison with mixed-fed infants (open circles) receiving formula and/or solid food in addition to breast milk. The numbers in parentheses refer to the number of subjects. Vertical bars indicate SDs; $\mathrm{nmol} / \mathrm{ml}=\mu \mathrm{mol} /$ liter.

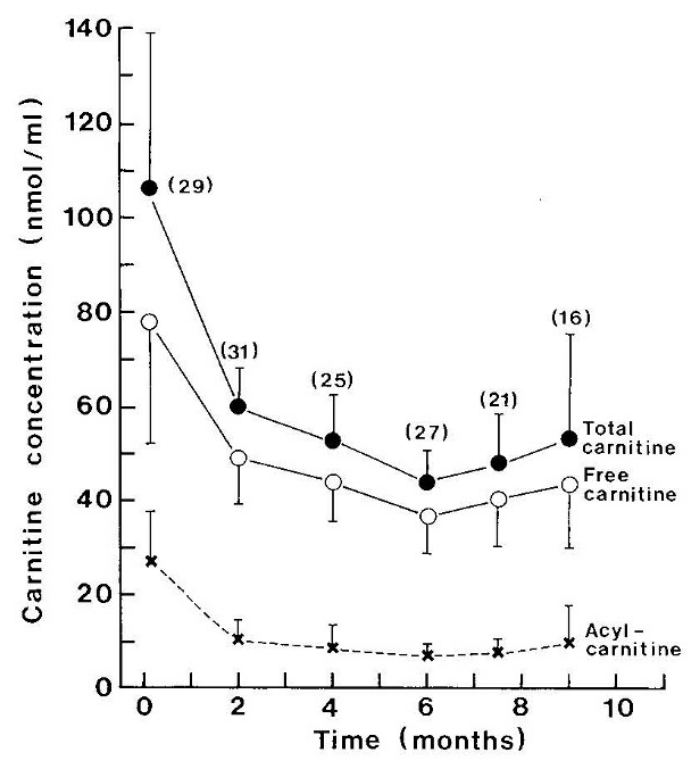

Fig. 2. Carnitine concentration in breast milk during lactation. The total (closed circles), free (open circles), and acylcarnitine (crosses) in breast milk during prolonged breast feeding from birth to 9 months. The numbers in parentheses refer to the number of milk samples. Vertical bars indicate SDs; $\mathrm{nmol} / \mathrm{ml}=\mu \mathrm{mol} /$ liter.

carnitine concentration in the infants was significantly higher ( $p$ $<0.001)$ than in the mothers. The difference disappeared after 9 months.

The total carnitine concentrations in the serum of the mothers at the time of delivery correlated positively $(r=0.51, p<0.01)$ with the total carnitine levels of cord blood. Despite breast feeding, the carnitine concentrations of the mothers and their infants did not correlate later.

Carnitine concentration in breast milk. In breast milk the means of the total (106 $\mu \mathrm{mol} /$ liter $)$, free $(78 \mu \mathrm{mol} / \mathrm{liter})$, and acylcarnitine $(28 \mu \mathrm{mol} /$ liter $)$ concentrations were high immediately after delivery (Fig. 2). Acylcarnitine represented about $30 \%$ of the total carnitine. The means of the total, free, and acylcarnitine concentrations decreased significantly $(p<0.001)$ during the first 2 months after delivery and remained unchanged thereafter (Fig. 2). Two months after delivery the mean total carnitine concentration in breast milk had decreased to the serum level of 
the mothers. At the same time the proportion of acylcarnitine had decreased below $20 \%$ of the total carnitine.

In the formula the total, free, and acylcarnitine concentrations were 204, 137, and $67 \mu \mathrm{mol} /$ liter.

During sole breast feeding the infants' mean intake of carnitine per day, calculated from the ingested milk volumes and the total carnitine concentrations, was $5.7 \mu \mathrm{mol} / \mathrm{kg}$ (range 4.6-6.5) at 4 months of age, $4.7 \mu \mathrm{mol} / \mathrm{kg}$ (range 3.4-7.5) at 6 months, and $6.0 \mu \mathrm{mol} / \mathrm{kg}$ (range $3.2-8.2$ ) at 9 months. The serum concentrations of the total carnitine in the infants did not correlate with the carnitine intakes from breast milk. Neither did the serum concentrations of the total carnitine in the mothers correlate with the carnitine contents of breast milk.

During sole formula feeding the infants' mean intake of carnitine per day, calculated from the total carnitine concentration and the volume of formula consumed, was $28.9 \mu \mathrm{mol} / \mathrm{kg}$ (range $26.0-31.0$ ) at 1 month of age and $30.7 \mu \mathrm{mol} / \mathrm{kg}$ (range 17.0 $4.10)$ at 2 months.

\section{DISCUSSION}

The mean level of the total carnitine was in the mixed cord blood lower than in the serum of the mothers. In earlier reports the carnitine level in cord blood has been found to be either similar $(23)$ or higher $(8,24,25)$ than in mothers. In the present study the blood samples from the mothers were taken 3-4 days after delivery whereas in previous studies $(8,23-25)$ the samples have been taken at the time of delivery. This provides an explanation for our finding because serum carnitine levels of pregnant women are low $(24,26)$ but increase during the 1st wk after delivery (18).

Despite the above difference in the sampling time between our infants and mothers, serum carnitine levels of the mothers correlated positively with carnitine levels of cord blood, in agreement with previous studies $(8,23,25)$. Carnitine in the newborn infant may derive from fetal synthesis or placental transport. However, indirect evidence suggests that fetal carnitine synthesis is low (4-15) whereas in vitro perfusion experiments imply that the human placenta at term plays an active role in carnitine metabolism by supplying carnitine to the fetus (27).

The mean serum level of the total carnitine was during months 2-9 higher in the breast-fed infants than in their mothers. In an earlier report, carnitine concentration in the plasma of term infants was low at birth and increased to the adult level in 6 months (28). More than half of plasma carnitine may exist in the form of esters in newborns, in certain diseases, and during starvation (29). This provides an explanation for our finding because we measured the total carnitine concentration whereas only free carnitine has been measured in previous studies (16, 29).

The relationship between serum and tissue carnitine depends not only on serum level but also on cellular uptake and turnover. Carnitine uptake mechanisms requiring energy have been suggested to undergo a maturation process during fetal development (30). In agreement with this suggestion, carnitine concentrations of tissues are lower and carnitine concentrations of plasma higher in premature than term infants at birth $(30,31)$. In the present study serum carnitine concentration during months 2-9 was found to be higher in infants than in the mothers. This could be explained by assuming that the maturation of the cellular uptake mechanisms of carnitine continues after birth.

In most sucking animals fatty acid levels in blood are higher and fatty acid utilization is better during suckling than before birth or after weaning (32-34). Carnitine is known to enhance glycerol release from subcutaneous adipose tissue fragments taken from newborns (35). Carnitine also activates ketogenesis in the perfused liver of the rat (36). Thus, the high serum carnitine concentrations of our infants are in accordance with the high energy demands of growth and with the high fat content of breast milk and formula.
The mean total carnitine concentration in the serum of the mothers remained constant during prolonged lactation. The serum carnitine of the mothers $(50+11 \mu \mathrm{mol} /$ liter $)$ was similar to the serum carnitine of nonpregnant women $(56+14 \mu \mathrm{mol} /$ liter) measured in our laboratory. In addition, the carnitine content of breast milk, measured at 4, 6, and 9 months, was found to remain constant during lactation. Thus, our findings do not support the suggestion that healthy women require supplementary carnitine during lactation (1).

Immediately after delivery the mean level of the total carnitine in breast milk was higher than reported previously (16-18). This difference may result from methodological difficulties caused by caramel formation from acylcarnitine during measurement (18). Although recoveries were much better for acetyl than palmitoyl carnitine, we did not assess them separately, because palmitoyl carnitine seldom accounts for a significant proportion of the total carnitine. Carnitine levels in breast milk decreased during the first 2 months of lactation, in agreement with previous reports $(17,18)$. However, milk carnitine remained constant after 2 months during prolonged breast feeding.

In our infants carnitine intake from breast milk was 3.8-8.2 $\mu \mathrm{mol} / \mathrm{kg} /$ day at the age of 4-9 months. This is similar to the carnitine intake from the normal adult diet in United States (37). Carnitine intake in neonates has been suggested to correlate with serum carnitine when carnitine intake is high or low $(9,14)$. Within the range measured in our study, carnitine intake did not, however, correlate with the serum carnitine concentration of the infants.

The total carnitine concentration in our formula was 204 $\mu \mathrm{mol} /$ liter; similar concentrations have been reported previously (38). In the formula-fed infants aged 1-2 months the intake of carnitine was five times higher than in breast-fed infants aged 49 months whereas the mean serum concentrations of the total carnitine were similar in the breast-fed and formula-fed infants. Although serum level of carnitine may be a poor indicator of carnitine status, our finding agrees with the suggestion that bioavailability of carnitine is better from breast milk than formula (16). The reason for the greater bioavailability from breast milk is unknown, because information about the absorption of carnitine from the gastrointestinal tract is limited $(39,40)$.

Newborn infants develop carnitine shortage during carnitinefree nutrition probably because carnitine synthesis is insufficient. In the present study we showed that prolonged sole breast feeding had no reducing effect on the serum carnitine of infants.

\section{REFERENCES}

1. Borum PR 1983 Carnitine. Ann Rev Nutr 3:233-259

2. Broquist HP, Borum PR 1982 Carnitine biosynthesis. Adv Nutr Res 4:181204

3. Tao RC, Yoshimura NN 1980 Carnitine metabolism and its application in parenteral nutrition. JPEN 4:469-486

4. Borum PR 1981 Possible carnitine requirement of the newborn and the effect of genetic disease on the carnitine requirement. Nutr Rev 39:385-390

5. Novak M, Wieser PB, Buch M, Hahn P 1979 Acetylcarnitine and free carnitine in body fluids before and after birth. Pediatr Res 13:10-15

6. Slonim AE, Borum PR, Tanaka K, Stanley C, Kasselberg AG, Greene HL, Burr IM 1981 Dietary-dependent carnitine deficiency as a cause of nonketotic hypoglycemia in an infant. J Pediatr 99:551-556

7. Schiff D, Chan G, Seccombe D, Hahn P 1979 Plasma carnitine levels during intravenous feeding of the neonate. J Pediatr 95:1043-1046

8. Novak M, Monkus EF, Chung D, Buch M 1981 Carnitine in the perinatal metabolism of lipids I. Relationship between maternal and fetal plasma levels of carnitine and acylcarnitines. Pediatrics 67:95-100

9. Penn D, Schmidt-Sommerfeld E, Wolf H 1980 Carnitine deficiency in premature infants receiving total parenteral nutrition. Early Hum Dev 4:23-34

10. Rovamo LM 1985 Postheparin plasma lipases and carnitine in infants during parenteral nutrition. Pediatr Res 19:292-296

11. Penn D, Schmidt-Sommerfeld E, Pascu F 1981 Decreased tissue carnitine concentrations in newborn infants receiving total parenteral nutrition. J Pediatr 98:976-978

12. Schmidt-Sommerfeld E, Penn D, Wolf H 1983 Carnitine deficiency in premature infants receiving total parenteral nutrition: effect of L-carnitine supplementation. J Pediatr 102:931-935

13. Orzali A, Donzelli F, Enzi G, Rubaltelli F 1983 Effect of carnitine on lipid 
metabolism in the newborn I. Carnitine supplementation during total parenteral nutrition in the first 48 hours of life. Biol Neonate 43:186-190

14. Penn D, Ludwige B, Schmidt-Sommerfeld E, Pascu F 1985 Effect of nutrition on tissue carnitine concentrations in infants of different gestational ages. Biol Neonate 47:130-135

15. Rebouche CJ, Engel AG 1980 In vitro analysis of hepatic carnitine biosynthesis in human systemic carnitine deficiency. Clin Chim Acta 106:295-300

16. Warshaw JB, Curry E 1980 Comparison of serum carnitine and ketone body concentrations in breast- and in formula-fed newborn infants. $\mathbf{J}$ Pediatr 97:122-125

17. Schmidt-Sommerfeld E, Novak M, Penn D, Wieser PB, Buch M, Hahn P 1978 Carnitine and development of newborn adipose tissue. Pediatr Res 12:660664

18. Sandor A, Pecsuvac K, Kerner J, Alkonyi I 1982 On carnitine content of the human breast milk. Pediatr Res 16:89-91

19. Salmenperä L, Perheentupa J, Siimes MA 1985 Exclusively breast-fed healthy infants grow slower than reference infants. Pediatr Res 19:307-312

20. Robles-Valdes C, McGarry D, Foster DW 1976 Maternal-fetal carnitine relationships and neonatal ketosis in the rat. J Biol Chem 251:6007-6012

21. McGarry JD, Foster DW 1976 An improved and simplified radioisotopic assay for the determination of free and esterified carnitine. J Lipid Res 17:277281

22. Dixon WJ 1981 BMDP Statistical Software. University Press, Berkeley

23. Schmidt-Sommerfeld E, Penn D, Wolf $\mathrm{H} 1981$ The influence of maternal fat metabolism on fetal carnitine levels. Early Hum Dev 5:233-242

24. Bargen-Lockner C, Hahn P, Wittman B 1981 Plasma carnitine in pregnancy. Am J Obstet Gynecol 140:412-414

25. Cederblad G, Niklasson A, Rydgren B, Albertsson-Wikland K, Olegård R 1985 Carnitine in maternal and neonatal plasma. Acta Paediatr Scand 74:500504

26. Scholte HR, Jennekens FG 1978 Low carnitine levels in serum of pregnant women. N Engl J Med 299:1079-1080

27. Schmidt-Sommerfeld E, Penn D, Sodha RJ, Prögler M, Novak M, Schneider
H 1985 Transfer and metabolism of carnitine and carnitine esters in the in vitro perfused human placenta. Pediatr Res 19:700-706

28. Battistella PA, Vergani L, Donzelli F, Rubaltelli F, Angelini C 1980 Plasma and urine carnitine levels during development. Pediatr Res 14:1379-138

29. Hahn P 1985 Carnitine and ketones in the perinatal period. Fed Proc 44:2339 2341

30. Shenai JP, Borum PR, Mohan P, Donlevy SC 1983 Carnitine status at birth of newborn infants of varying gestation. Pediatr Res 17:579-582

31. Shenai JP, Borum PR 1984 Tissue carnitine reserves of newborn infants. Pediatr Res 18:679-681

32. Hahn P, Novak M 1985 How important are carnitine and ketones for the newborn infants. Fed Proc 44:2369-2373

33. Hahn P 1978 Lipids. In: Stave U (ed) Perinatal Physiology, 2nd ed. Medical Book Co, New York, pp 397-423

34. Girard J, Duee PH, Ferre P, Pegorier JP, Escriva F, Decaux JF 1985 Fatty acid oxidation and ketogenesis during development. Reprod Nutr Dev 25:303319

35. Novak M, Penn-Walker D, Hahn P, Monkus EF 1975 Effect of carnitine on lipolysis in subcutaneous adipose tissue of newborns. Biol Neonate 25:8594

36. McGarry JD, Robles-Valdes C, Foster DW 1975 Role of carnitine in hepatic ketogenesis. Proc Nat Acad Sci USA 72:4385-4388

37. Rebouche CJ, Engel AG 1984 Kinetic compartmental analysis of carnitine metabolism in the human carnitine deficiency syndromes. J Clin Invest 73:857-867

38. Borum PR, York CM, Broquist HP 1979 Carnitine content of liquid formulas and special diets. Am J Clin Nutr 32:2272-2276

39. Gudjonsson H, Li BUK, Shug AL, Olsen WA 1985 In vivo studies of intestinal carnitine absorption in rats. Gastroenterology 88:1880-1887

40. Gudjonsson H, Li BUK, Shug AL, Olsen WA 1985 Studies of carnitine metabolism in relation to intestinal absorption. Am J Physiol 248:G313G319 